\title{
Retraction Note to: Effect of Carbon Content on the Electrical Conductivity of Carbon Black-Filled PMC with Various Matrices
}

\section{Soon-Gi Shin ${ }^{1}$}

Published online: 19 February 2018

(c) The Korean Institute of Metals and Materials 2018

\section{References}

1. Shin, S.G.: Electron. Mater. Lett. 7, 237 (2011). https://doi. org/10.1007/s13391-011-0911-3

The Editor-in-Chief and Editorial Board of Electronic Materials Letters have retracted this article [1] because its contents have been previously published by Miyasaka et al. [2]. The contents of this article are therefore redundant. Author Soon-Gi Shin has not responded to correspondence from the Editor about this retraction.

The original article can be found online at https://doi.org/10.1007/ s13391-011-0911-3.

Soon-Gi Shin

ssg@ kangwon.ac.kr

1 Department of Advanced Materials Engineering, College of Samcheok, Kangwon National University, Samcheok-si, Gangwon 245-711, Korea

2. Miyasaka, K., Watanabe, K., Jojima, E., et al.: J. Mater. Sci. 17, 1610 (1982). https://doi.org/10.1007/BF00540785 